\title{
Democratização e mudanças práticas na gestão escolar
}

Arilene Maria Soares de Medeiros

Universidade do Estado do Rio Grande do Norte

\section{Resumo}

Este artigo discute o processo de democratização da gestão em Mossoró/RN, com evidência nas mudanças ocorridas na prática do diretor escolar após processo seletivo para assumir o cargo. Trata-se de uma pesquisa qualitativa com aplicação de questionários aos profissionais atuantes nos estabelecimentos de ensino: diretores, vice-diretores, supervisores e professores. Os resultados revelam que os diretores são bem avaliados nos seguintes quesitos: permanência e presença na escola, comprometimento com as questões pedagógicas, responsabilidade pela educação pública. Contudo, a democratização da gestão permanece insuficiente para desenvolver a independência e a autonomia dos diretores frente ao sistema, demonstrando que a gestão democratizada precisa ser aperfeiçoada em suas bases teóricas e práticas.

Palavras-chave: Democratização da gestão. Direção escolar. Autonomia. 


\section{Democratization and practical changes in school administration}

This article discusses the process of democratization of school administration in Mossoró/RN, showing evidence of changes in the practice of the school principal after coming into office through a selection process. This is a qualitative research project, in which questionnaires were applied to professionals working in schools: principals, vice-principals, supervisors and teachers. The results show that the directors are well evaluated in the following categories: permanence and presence at the school, commitment to pedagogical issues, and responsibility towards public education. However, the democratization of administration remains insufficient to develop the independence and autonomy of principals from the system, demonstrating that democratized administration needs to be improved in its theoretical and practical bases.

Keywords: Democratization of administration. School principal. Autonomy.

\section{Democratización y cambios en las prácticas de gestión de la escuela}

Este artículo aborda el proceso de democratización de la gestión en Mossoró/RN, con la evidencia de los cambios en la práctica de dirección de la escuela después del proceso de selección para el cargo. Se trata de una investigación cualitativa, para lo cual se aplican cuestionarios a los profesionales que trabajan en las escuelas: los directores, vice-directores, supervisores y profesores. Los resultados muestran que los directores son bien evaluados en las categorías: permanencia y presencia en la escuela, el compromiso con las cuestiones pedagógicas, la responsabilidad pela educación pública. Sin embargo, la democratización de la gestión sigue siendo insuficiente para desarrollar la independencia y la autonomía de los directores en relación al sistema, lo que demuestra que la gestión democratizada precisa ser perfeccionada en sus bases teóricas y prácticas.

Palabras clave: Democratización de la gestión. Director Escolar. Autonomía. 


\section{Introdução}

A democratização da gestão escolar precisa ser enfatizada dentro de um quadro teórico amplo que venha explicitá-la no conjunto das novas configurações do Estado face à democracia. É inegável a transformação da democracia durante todo o século $X X, e$ até mesmo a tendência hegemônica, realçada pela democracia representativa, vem sendo questionada diante das novas demandas sociais, consequência das lutas históricas em prol da cidadania, da participação e da inclusão.

Toda e qualquer discussão que se proponha discorrer em torno da democratização da gestão exige que se pontuem os limites e as diferentes (ou possíveis) formas que a democracia vem assumindo nos espaços sociais e educacionais. Para Santos (2002), no âmbito das teorias hegemônicas, a democracia associa-se, quase que exclusivamente, ao desenvolvimento das formas de governo e da escolha dos representantes políticos pelas populações que por eles serão representadas. Trata-se da tão conhecida e propalada democracia representativa. De modo geral, pode-se afirmar que durante o século XX as sociedades tornaram-se democráticas mediante a escolha pelo voto direto dos chefes de governo e parlamentares. A democracia representativa - embora necessária às sociedades - não deixa de demonstrar sua fragilidade e baixa intensidade, haja vista os próprios chefes de governos e parlamentares serem os principais protagonistas do desrespeito à coisa pública.

Por sua vez, as teorias contra-hegemônicas vêm sendo discutidas por diversos estudiosos e estudiosas, que propõem discutir a democracia não apenas na esteira hegemônica da representatividade, mas como "uma gramática da organização da sociedade e da relação entre Estado e a sociedade" (Santos, 2002, p. 51). Sendo assim, a democracia não é mais concebida apenas como uma forma de governo; é também forma de organização frente ao Estado e à própria sociedade. Concebe-se, portanto, a democracia participativa como sendo uma nova organização social na e pela qual são reinventadas estratégias de enfrentamento do poder político e ideológico global chamado de neoliberalismo. Na realidade, a democracia participativa provoca maior impacto na sociedade, haja vista sua capacidade de enfrentar os desafios da inclusão e do respeito ao multiculturalismo. A democracia participativa sugere uma articulação com a democracia representativa, pois a primeira também se respalda na participação em conselhos diversos criados, por vezes, pelo próprio Estado e, por outras, pela sociedade civil organizada, fazendo-nos entender que a luta está acontecendo dentro e fora do Estado.

No contexto em que a democracia está sendo entendida como a construção de uma nova gramática social por meio da qual se incluem as diferentes culturas, os diferentes 
sujeitos, cabe-nos fazer as possíveis articulações entre esse debate mais amplo que perpassa a compreensão da democracia na contemporaneidade e o processo de democratização da gestão ensejado pela política educacional mossoroense. Como e de que forma nasce o processo de democratização da gestão escolar na realidade de Mossoró? Quais seus limites e perspectivas? Há inclusão? Como podemos avaliar sua intensidade?

Este artigo discute o processo de democratização da gestão nas escolas públicas municipais de Mossoró - RN, dando ênfase às mudanças na postura do diretor escolar decorrentes do processo de democratização do acesso ao cargo nas escolas públicas municipais de Mossoró1. A premissa básica que fundamenta este estudo é a de que a democratização do acesso produz ou pode produzir alterações nas atitudes, comportamentos, procedimentos; alterações que provavelmente deixariam de existir se o acesso fosse materializado pelos canais da arbitrariedade política dos sistemas. Desta feita, advogamos que a democratização da gestão, tendo em foco os mecanismos que levam os diretores e diretoras a seus cargos, pode influenciar o comprometimento com a instituição e, consequentemente, com a educação que se pretende nela.

A democratização da gestão é tema bastante complexo por causa de sua interface com as políticas públicas educacionais que nem sempre representam efetivamente a democratização da gestão ou a concretização dos interesses coletivos. Essa nãorepresentação é nítida quando o poder local insiste na manutenção de práticas conservadoras que dificultam a democracia, como é o caso de Mossoró - RN, cujas evidências estariam presentes na própria forma de escolha dos dirigentes escolares que insistem na conservação de práticas clientelistas. As insistências são reais não apenas no sistema educacional mossoroense, mas em vários sistemas de nossa federação que continuam, por razões diversas, desconsiderando as prerrogativas constitucionais e legais do princípio da gestão democrática no ensino público. A título de ilustração, os sistemas municipais do Rio Grande do Norte são expressivos nessa perspectiva; são raros os que estão atuando de maneira a coibir práticas clientelistas quando a matéria em pauta refere-se aos mecanismos de como os diretores lou equipes diretoras) chegam efetivamente aos seus cargos². $^{2}$.

1. Pesquisa realizada no período 2006-2007, financiada pelo CNPq, com a participação do acadêmico de Pedagogia da UERN Allan Solano Souza.

2. Foi realizada no período de 2008-2009 uma pesquisa sobre a Democratização da Gestão nos Sistemas Municipais da Região Oeste Potiguar, que compreende oito municípios: Areia Branca, Baraúnas, Governador Dix-Sept Rosado, Grossos, Mossoró, Serra do Mel, Tibau e Upanema, contando com o financiamento do CNPq e com a participação dos acadêmicos de Pedagogia da UERN, Allan Solano Souza e Ítalla Taciany Freitas de Lima. Além de Mossoró, apenas o Sistema Municipal de Upanema vem desenvolvendo ações na perspectiva de assegurar mecanismos de escolha democrática do diretor escolar. 
Reconhece-se a democratização da gestão como consequência do movimento democrático que, no Brasil, coincide, quer de maneira explícita ou não, com o movimento da redemocratização do país, nos anos de 1980. A problemática da democracia limitada no âmbito da sociedade brasileira e, consequentemente, na educação, revela-nos o quanto a democracia em nosso meio demonstra ser tardia e, ao mesmo tempo, instável, se considerarmos os períodos históricos em que ela se sobrepunha à autocracia (Saes, 2001). Para o referido autor, o período pós-Constituição de 1988 é o mais profícuo da democracia constitucional brasileira, mesmo assim, permanece "[...] diante de uma experiência democrática que se revela pouco desenvolvida quando comparada com o padrão democrático vigente nos países capitalistas centrais. Nesse ponto, impõe-se refletir sobre as perspectivas dessa democracia no Brasil atual" (Saes, 2001, p. 128).

As experiências democráticas no Brasil exprimem o quão nossa democracia reflete a crise de legitimação no aparelho estatal (Habermas, 1999), que ganha materialidade na forma das regras do jogo político-partidário. Na realidade, este trabalho não tem maiores pretensões em discutir as disfunções ou injunções da política local, mas refletir sobre a democratização da gestão mediante a proposição do sistema público municipal de Mossoró, no Rio Grande do Norte, identificando seus limites e perspectivas nas mudanças práticas do ou da dirigente no cotidiano escolar.

\section{Democratização da Gestão: perspectivas e limites políticos no contexto local}

Em Mossoró ${ }^{3}$, desde 2003, a Prefeitura vem desenvolvendo uma parceria com 0 Instituto Airton Senna, a qual exigiu que o poder público local adotasse uma nova política educacional tendo que incluir o modelo de escolha/seleção de diretores escolares como forma de romper o círculo vicioso da indicação política. A parceria com o Instituto Airton Senna demonstra que o processo de democratização da gestão não foi fruto direto das lutas desencadeadas pela sociedade civil organizada em nível local, nem da "sensibilidade" do poder público em adequar seus procedimentos políticos às recomendações legais, mas de exigências exógenas (Medeiros; Sousa, 2007a). Diga-se de passagem, o referido Instituto impôs a democratização do acesso ao cargo de diretor ou diretora escolar como condição primeira para que o sistema público municipal de ensino de Mossoró pudesse firmar tal parceria.

3. É preciso esclarecer que esta cidade é a segunda maior cidade do Rio Grande do Norte, com aproximadamente 250 mil habitantes. Destaca-se economicamente por ser a maior produtora de petróleo em terra do país e a maior exportadora de sal marinho interna e externamente. 
Nessa localidade, a Constituição - nossa Carta Magna de 1988, que já tem mais duas décadas de existência -, a Lei de Diretrizes e Bases da Educação Nacional, nº 9.394/96 e o Plano Nacional de Educação, Lei n ${ }^{10.172 / 01}$ parecem não ter força jurídica suficiente para fazer acontecer o princípio da "gestão democrática do ensino público". Nesse sentido, infere-se que a disposição de leis não tem interferido de maneira efetiva na concretização da gestão democrática do ensino público, uma vez que esta necessita de uma parceria externa - com suas imposições - que provoque as primeiras iniciativas políticas para sua efetivação.

Obviamente a gestão democrática é mais ampla e complexa do que a escolha de diretores; no entanto, para efeitos de delimitação, estamos discutindo-a a partir desse ponto. A democratização da gestão pela via do acesso ao cargo de diretor ou diretora escolar apresenta inúmeros limites e contradições, porém, sinaliza um primeiro passo para o rompimento de práticas conservadoras quanto à escolha destes profissionais. 0 poder político local passou a utilizar-se desses requisitos legais e constitucionais somente em 2003, quando tornou público o primeiro processo seletivo ao cargo de diretor ou diretora escolar mediante a promulgação da Lei $n^{\circ} 1.856 / 2003$, que institui as normas para o processo de seleção ao cargo ${ }^{4}$.

A seleção para o cargo apresenta limites na medida em que exclui do processo os vice-diretores e vice-diretoras das escolas de Ensino Fundamental e dirigentes dos estabelecimentos de Educação Infantil. Isso indica que o discurso oficial da democratização da gestão se concretiza de modo acanhado por permanecer atrelado ao clientelismo ${ }^{5}$, e que o sistema de ensino de Mossoró não está completamente aberto às mudanças requeridas à gestão escolar de modo a atender aos requisitos mínimos da democracia representativo-participativa.

Se a democracia consiste numa nova gramática social em que o Estado e a sociedade civil, com suas instituições e movimentos sociais, estabelecem mecanismos e estratégias de organização a partir da disposição de regras cada vez mais abertas e plurais para atender à diversidade cultural tão evidenciada hoje, percebe-se que, em Mossoró, as regras dessa nova gramática social, na qual a participação torna-se uma estratégia nuclear, têm um longo percurso a ser percorrido no contexto da democratização da gestão, a qual é aqui analisada.

4. Além dessa lei que trata especificamente da democratização da Gestão, prevendo processo seletivo para o cargo de diretor(a) escolar, duas outras leis foram instituídas: a Lei no 1.827/2003 - Programa de Manutenção das Escolas Municipais/PROMEM -, que estabelece a autonomia financeira das escolas; a Lei no 1.855/2003 - Gestão Democrática do ensino público da Rede Municipal -, cujo foco é a autonomia pedagógica e administrativa das escolas.

5. Farias (2000) nos faz entender que o clientelismo é apropriação privada da coisa pública, inerente à concepção liberal de democracia, que utiliza como estratégia a barganha político-eleitoral. 0 autor radicaliza sua posição no sentido de demonstrar que o clientelismo, que não se confunde com coronelismo, no fundo, não pode ser eliminado no contexto das sociedades capitalistas, porque é condição fundante para permanência do estado de coisas, como a manutenção dos interesses sociais de dominação e dependência pessoal. 


\section{Democratização da gestão: mudanças práticas do cargo de diretor ou diretora escolar sob a ótica dos profissionais}

Considera-se neste item os aspectos considerados por diretores, vice-diretores, supervisores e professores quanto às mudanças ocasionadas na postura profissional dos dirigentes escolares decorrente do processo de democratização do acesso ao cargo. Admite-se que esse processo pode possibilitar um caminho de mão dupla: o exercício democrático por parte do poder local, cuja escolha do diretor se pauta em outros parâmetros e, em decorrência disto, as possíveis mudanças na postura profissional de quem está respondendo pela função de diretor ou diretora escolar não somente para "agradar" aos superiores.

Com a democratização da gestão, é de se esperar que o diretor ou diretora selecionado(a), como é o caso em evidência, assuma uma postura mais profissionalizada porque comprometida com as questões internas da escola. Não que a escolha direta dos dirigentes seja o único determinante do processo de democratização da gestão, mas este é determinado, num menor ou maior grau de implicação, por aquela. Ou seja, a forma como o diretor ou diretora tem acesso ao cargo pode provocar mudanças práticas no fazer cotidiano da gestão escolar. "0 processo de escolha é apenas um dos múltiplos determinantes a influir na maneira de gerir a escola e, em especial, no sentido de agir do próprio diretor escolar" (Paro, 2001, p. 68).

A presente pesquisa compreendeu um conjunto de 11 escolas da zona urbana de Mossoró - RN, perfazendo a totalidade de escolas que tiveram seus diretores selecionados no ano de $2006^{6}$. Participaram 59 profissionais assim distribuídos: 11 diretores escolares selecionados; 05 vice-diretores não incluídos no processo seletivo; 20 supervisoras e 23 professores de diferentes áreas de formação.

Os profissionais que participaram da pesquisa revelaram que o processo de democratização da gestão provocou mudanças na postura do dirigente escolar, principalmente quando se observa um conjunto de atitudes, comportamentos e procedimentos que está contribuindo para um melhor desempenho destes profissionais na escola. Tal conjunto, ao ser articulado em sua totalidade, busca apreender a complexidade que envolve o processo de democratização da gestão, iniciado obviamente na escolha do diretor ou diretora e prolongado nas ações cotidianas, exigindo dos mesmos uma nova postura profissional.

6. 0 processo seletivo consiste em três fases: $1^{\mathrm{a}}$ - aferição de conhecimento mediante prova escrita a partir de uma referência bibliográfica sugerida no ato da inscrição, de caráter eliminatório; $2^{a}$ - curso preparatório sobre gestão, ministrado pelo Instituto Airton Senna, cujas referências são suas "Cartilhas" do modelo de gestão Nota 10, também de caráter eliminatório; $3^{\text {a }}$ e última - entrevista realizada com a equipe responsável pelo processo seletivo. 
$\mathrm{Na}$ tentativa de demonstrar o que estamos argumentando, a figura abaixo procura ser a síntese do conjunto de atitudes e comportamentos do diretor ou diretora escolar frente ao processo de democratização da gestão. A figura explicita desde o primeiro aspecto que se diferencia da época em que os dirigentes eram escolhidos arbitrariamente pelo poder local, que diz respeito a sua permanência e presença na instituição na qual está para dirigir, até os demais aspectos em distribuição crescente de complexidade, conforme indicação das setas. Da permanência e presença na escola à autonomia do diretor ou diretora está o grande desafio que se pretende imprimir a uma gestão autenticamente democratizada.

\section{Figura 1: Mudanças na postura profissional do Diretor Escolar face à democratização da gestão}

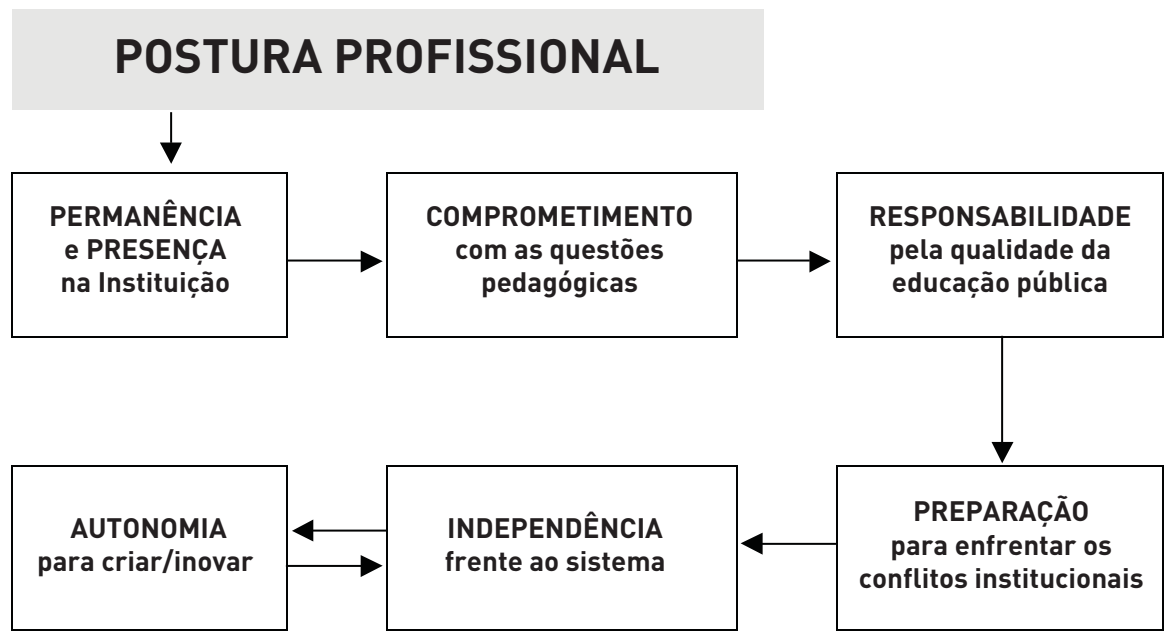

Desenvolver uma compreensão da postura profissional do diretor ou diretora escolar supõe o entrelaçamento de vários aspectos. Aqui não se trata de definir uma postura profissional ideal para um dirigente escolar real, mas de eleger alguns aspectos que se tornam indispensáveis à construção de uma postura profissional compatível ao processo de democratização da gestão, o qual procura desvencilhar-se dos pressupostos inerentes à gestão técnico-científica, cujas referências práticas são centralidade e neutralidade (Libâneo, 2004).

Com as mudanças no âmbito da gestão, exige-se também que o diretor ou diretora mude suas atitudes, comportamentos e procedimentos no dia-a-dia de seu fazer. Esse conjunto de atitudes e comportamentos, sintetizado na figura exposta acima, não pode 
ser lido linearmente, sob o risco de congelar uma dinâmica que é inerente às mudanças dentro da escola a partir da ação profissional do dirigente escolar. A pretensão de democratizar a escola internamente requer dos profissionais que estão na linha de frente da escola um movimento que vai de sua permanência e presença na instituição à autonomia, demonstrando o quão complexa se torna a administração de uma escola democrática. Portanto, de comportamentos e atitudes relativamente mais simples aos mais complexos, está o diretor ou diretora tentando dar conta de uma outra postura profissional.

Permanência e presença na instituição demonstram uma atitude de menor complexidade se comparada às demais, porém não menos importante. Aliás, um diretor ou diretora presente é o primeiro passo a ser considerado, pois não se tem diretor comprometido quando este, por alguma razão, torna-se um profissional ausente, reforçando seu isolamento e desconhecimento frente aos problemas e às questões cotidianas que dizem respeito à escola. 0 diretor ou diretora ausente acaba se transfor-mando num profissional relapso, desacreditado pelos pares, porque descomprometido com os interesses e expectativas do coletivo da escola. Esse aspecto não deveria, mas realmente se relaciona à forma de chegar ao cargo. Tanto é verdade essa assertiva que somente após a adoção de processo seletivo democrático é que os diretores e diretoras das escolas municipais de Mossoró se tornaram mais presentes, conforme ficou demonstrado nos questionários. A forma como o diretor ingressa no cargo pode refletir - sem atribuir generalizações - sua responsabilidade frente à instituição ou o poder político local.

A presença do diretor ou diretora na escola deveria ser uma responsabilidade dos profissionais comprometidos em acompanhar e contribuir com a solução dos sérios problemas que enfrentam no seu dia-a-dia. 0 diretor ou diretora enquanto profissional selecionado surge para atuar na função diretiva da escola porque demonstrou knowhow, e não para ser profissional 'fantasma', aparecendo de vez em quando para cuidar de assuntos esporádicos, como se o fazer cotidiano de uma escola pública fosse uma mera eventualidade.

Avançando na discussão: não basta permanecer na escola, marcar presença, é necessário comprometer-se com as questões pedagógicas. Talvez aqui resida um dos maiores dilemas que envolvem o diretor ou diretora escolar e sua função dentro da escola. Pois, opondo-se às constantes reclamações que acusam diretores por falta de envolvimento e comprometimento com as questões pedagógicas, há uma expectativa de que cumpram a sobrecarga burocrática que incide sob sua prática, advinda do próprio sistema. Há uma indagação que se faz comumente: como e de que forma o diretor ou diretora pode se comprometer com as questões pedagógicas se não há tempo nem espaço para isso? 
Essa indagação precisa ser discutida com enorme cuidado para que não se faça inferências pouco fundamentadas numa questão que atravessa a problemática teórica e prática da função de direção escolar (MEDEIROS, 2007b). Na realidade, o que dá identidade profissional ao dirigente escolar é exatamente aquilo que lhe custa bastante esforço, porque não há disposição de tempo nem de espaço: comprometer-se com as questões pedagógicas da escola. Formiga (2007), discutindo as dimensões administrativa e pedagógica na gestão escolar, reflete sobre três perspectivas teóricas distintas: i) funcional - implica em assegurar que os conflitos entre o administrativo e o pedagógico não se traduzam em conflitos pessoais nem sociais; ii) interconexão - reforça o pressuposto de que os conflitos entre o administrativo e o pedagógico na gestão são da ordem epistemológica; iii) multirreferencial - se apóia no pressuposto da pluralidade para admitir que a gestão escolar se ancora na perspectiva do indivíduo, da relação, do grupo, da organização e da instituição. A relação entre a dimensão administrativa e a pedagógica pauta-se, em geral, na exclusão de uma em detrimento de outra, mas precisa ser recolocada em outras bases, uma vez que elas devem estar imbricadas.

Isto em si já traduz um grande problema, pois o diretor ou diretora sabe que deve se comprometer com as questões pedagógicas, ou seja, com a política da escola em toda sua plenitude, no entanto, poucas são as ações feitas nesse sentido. De qualquer modo, após o processo seletivo, fica constatado que diretores estão se comprometendo mais com as questões do ensino e da aprendizagem, demonstrando um maior interesse com a qualidade da educação pública.

A partir desse momento, já se começa a introduzir o aspecto da responsabilidade pela qualidade da educação pública. É preciso reafirmar que não é possível fazer uma leitura/análise linear dos aspectos evidenciados, uma vez que eles se encontram intrinsecamente relacionados. 0 comprometimento com as questões pedagógicas presume uma articulação direta à responsabilidade pela qualidade da educação pública, uma vez que a garantia desta passa necessariamente pelo comprometimento com aquelas. Não é um dirigente simplesmente burocrata que irá se responsabilizar ou pelos menos empreender ações no sentido de fortalecer a qualidade da educação. De fato, o diretor ou diretora atento somente à burocracia, às demandas políticas do poder público local se esquiva de pensar outras dimensões de seu fazer.

É evidente que a qualidade da educação pública não é conferida apenas pela ação de diretores, mas vinculada à responsabilidade do próprio poder público e dos demais profissionais atuantes na escola. Antes da democratização da gestão, pouco se apontava a importância do diretor ou diretora frente a tal questão. A qualidade da educação pública passa a ser um aspecto fundamental aos dirigentes escolares democráticos. Constata-se, ainda, que sua principal responsabilidade não é mais responder copiosamente as 
demandas de um poder local, mas se (prelocupar com a vida da escola, com as questões pedagógicas. A educação se constitui num direito e sua qualidade é uma necessidade. Atualmente, o maior objetivo a ser buscado dentro das instituições educativas é a sua qualidade, e por ela devem se responsabilizar diretores, professores, supervisores, bem como o poder público e a sociedade civil, de modo geral.

A responsabilidade com a qualidade da educação pública exige determinação coletiva e definição clara dos propósitos e das ações administrativas e pedagógicas. Portanto, trata-se de um posicionamento político que a cada profissional da educação cabe assumir, e aos dirigentes particularmente. A busca pela qualidade da educação é uma ação complexa a ser enfrentada. Ela pressupõe enfrentamento dos conflitos institucionais internos e externos, pois nem sempre aquilo que o sistema pretende com a escola é o que a sociedade (a comunidade) deseja. E aqui já estamos nos valendo de outro aspecto: o da preparação do diretor ou diretora para enfrentar os conflitos institucionais.

Os conflitos externos passam pela interferência que o sistema exerce sobre a gestão da escola. São de ordem política. Eles se tornam mais intensos quando se está diante das políticas de democratização. Os conflitos internos dizem respeito ao modo como a escola se organiza, cabendo aos diretores não camuflá-los, mas administrá-los coletivamente. Não há escola sem conflitos, mas também não há escola que funcione pedagógica e administrativamente sem que eles sejam trabalhados e superados. Quando os conflitos são solucionados, outro clima organizacional se instala na instituição, favorecendo a qualidade de suas ações. Os dirigentes escolares precisam admitir que a presença dos conflitos dentro da escola pode chamar atenção para a necessidade de mudanças. Aliás, a convivência com os conflitos (externos e internos) é uma realidade inerente à função de diretor (MEDEIROS, 2007b).

Outro aspecto necessário à postura profissional do diretor ou diretora escolar democrático é o exercício da independência frente ao sistema. Quando se pensa em independência, está se articulando uma concepção mínima de liberdade, imprescindível à atuação autônoma. Tal exercício torna-se crucial, pois sem o mesmo as possibilidades de democratização da gestão no interior da escola ficam cada vez mais escassas. A probabilidade de se exercitar a independência cresce na medida em que os diretores assumem o cargo pela via de sua democratização, pois,quando as práticas clientelistas se materializam no âmbito da escolha do dirigente escolar, o que entra em vigor é a submissão, a impossibilidade de um enfrentamento mais direto quando necessário. Assumir uma postura crítica frente ao sistema, todavia, demarca certo grau de autonomia do profissional. Ou seja, torna-se imprescindível a qualquer profissional - seja ele diretor, vice-diretor, supervisor ou professor - um mínimo de liberdade (Paro, 2001), 
que permita atuar de maneira propositiva e seja constantemente desenvolvida no interior das escolas.

A autonomia para criar e inovar constitui-se numa questão fundamental a ser enfrentada pelo diretor ou diretora escolar. Constitui-se no aspecto mais complexo da postura destes profissionais. Não é à toa que os diretores não foram bem avaliados nesse quesito, o que demonstra a necessidade de se percorrer um longo caminho de construção. Barroso (1996,p.170) discute autonomia tomando duas referências de análise: decretada e construída, sendo que, na primeira, busca-se "desconstruir os discursos legitimadores de descentralização e de autonomia das escolas, [...] confrontando-as com as estruturas existentes e as contradições de sua aplicação prática". Por sua vez, na segunda, pretende-se "reconstruir os discursos das práticas", potencializando as estratégias de ação que a própria escola procura desenvolver e implementar. A autonomia se coloca sempre como uma questão relativa (Libâneo, 2004).

Efetivamente, a autonomia se configura como realidade individual e institucional, porque socialmente construída. A existência de uma autonomia no âmbito escolar requer profissionais com possibilidades de exercitar seu fazer com liberdade (Paro, 2001) e profissionalismo (Libâneo, 2004). Nesse sentido, a construção da autonomia profissional do diretor ou diretora escolar é condição sine qua non à democratização da gestão. Está bastante nítido que a autonomia não se faz por decreto ou por regulamentações. Muitas vezes, ela exige desregulamentação, ou seja, proceder diferentemente daquilo que está regulamentado (Cabral Neto; Silva, 2004). Portanto, não é legalizando a autonomia que ela se efetiva no contexto escolar, mas é no exercício e no enfrentamento das próprias convicções frente ao discurso do outro (oficial ou não) que ela realmente se constrói.

\section{Conclusões}

A experiência de democratização da gestão na realidade de Mossoró - RN apresenta inúmeras fragilidades, sendo mesmo de baixa intensidade, conforme apresentamos neste trabalho. No entanto, a democratização da gestão - via escolha de diretores - é um primeiro passo a ser dado para favorecer a democratização no interior da escola pública. Com a democratização da gestão, a qualidade pedagógica e administrativa da comunidade escolar ganha fôlego, e por isso a democratização precisa ser buscada constantemente por quem faz (in)diretamente a escola pública. Para isso, um primeiro passo tem de ser dado pelo sistema político, que deve se abrir à democracia como forma de coibir as práticas políticas arbitrárias que a contrariam; um segundo passo é a atuação de 
diretores mais presentes na gestão de uma escola pública, comprometidos com as questões pedagógicas, responsáveis pela qualidade da educação e, por fim, mais preparados para enfrentar os desafios e os conflitos internos e externos que envolvem a escola.

0 processo seletivo ao cargo de diretor ou diretora apresenta desafios frontais à democracia representativa e participativa, principalmente quando o sistema público de Mossoró, por algum obscurantismo, insiste em excluir da seleção democrática os cargos de vice-diretores das escolas de Ensino Fundamental e de diretores dos estabelecimentos de Educação Infantil, bem como desconsidera a participação da comunidade no processo de escolha do diretor ou diretora. Ainda assim, conclui-se que a democratização da gestão mediante processo seletivo foi capaz de provocar alterações na postura dos dirigentes escolares, mesmo que permaneça uma insuficiência na construção da independência e autonomia desses profissionais. Isso evidencia a necessidade de aprimoramento da gestão democratizada que, na essência, exige o enfrentamento de forças externas e internas para o exercício da independência política e autonomia de quem exerce funções diretivas. Sem estas, a democratização da gestão se enfraquece, pois democratização se articula política e epistemologicamente com a autonomia profissional do gestor ou gestora escolar.

\section{Referências}

BARROSO, João. 0 estudo da escola. Porto: Porto, 1996.

BRASIL. Constituição de 1988. 2. ed. República Federativa do Brasil. Brasília, Senado Federal, Centro Gráfico, 1988. 232 p.

BRASIL. Lei no 9.394/96, de 20 de dezembro de 1996. Estabelece as diretrizes e bases da educação nacional. Diário Oficial da União, Brasília, DF, 23 dez. 1996.

BRASIL. 2001. Lei n 10.172, de 9 de janeiro de 2001. Aprova o Plano Nacional de Educação e dá outras providências. Diário Oficial da União. Brasília, DF, 10 jan. 2001.

CABRAL NETO, Antônio; SILVA, Tatiane Campelo. Projeto Político-Pedagógico como mecanismo de autonomia escola. Revista Gestão em Ação, Salvador, v.7, n.1, p.7-23, jan./abr. 2004.

FARIAS, Francisco Pereira. Clientelismo e democracia capitalista: elementos para uma abordagem alternativa. Revista de Sociologia e Política, Curitiba, n. 15, p. 49-65, nov. 2000.

FORMIGA, Maria das Graças Freire. O Administrativo e o pedagógico na gestão escolar. Dissertação (Mestrado). Programa de Pós-Graduação em Educação da Universidade Metodista de São Paulo. São Bernardo do Campo. 2007.

HABERMAS, Jürgen. A crise de legitimação do capitalismo tardio. Tradução de Vamireh Chacon. 3. ed. Rio de Janeiro: Tempo Brasileiro, 1999.

LIBÂNEO, José Carlos. Organização e gestão da escola: teoria e prática. 5. ed. Goiânia: Alternativa, 2004. 
MEDEIROS, Arilene Maria Soares de; SOUSA, Allan Solano. Democratização do acesso ao cargo de diretor nas escolas públicas municipais de Mossoró - RN: proposições e discursos do sistema. In: XVIII ENCONTRO DE PESQUISA EDUCACIONAL DO NORTE E NORDESTE, 18, 2007, Maceió. Anais... Maceió: EdUFAL, 2007. p. 1-11.

MEDEIROS, Arilene Maria Soares de. Administração Educacional e racionalidade: o desafio pedagógico. ljuí: Editora da UNIJUÍ, 2007b.

MENDONÇA, Erasto Fortes. A regra e o jogo: democracia e patrimonialismo na educação brasileira. Campinas: Faculdade de Educação, UNICAMP, 2000.

PREFEITURA MUNICIAL DE MOSSORÓ. Lei no 1.827/2003, de 29 de agosto de 2993. Estabelece o Programa de Manutenção das Escolas Municipais, dando autonomia financeira às escolas. Mossoró, RN, Palácio da Resistência.

. Lei n 1.855/2003, de 27 de novembro de 2003. Estabelece a Gestão Democrática do ensino público da Rede Municipal, com foco na autonomia pedagógica e administrativa das escolas. Mossoró, RN, Palácio da Resistência.

. Lei no 1.856/2003, de 27 de novembro de 2003. Institui as normas para o processo de seleção para o cargo de diretor. Mossoró, RN, Palácio da Resistência.

SAES, Décio. República do Capital: capitalismo e processo político no Brasil. São Paulo: Boitempo, 2001. SANTOS, Boaventura de Sousa. Renovar a teoria crítica e reinventar a emancipação social. São Paulo: Boitempo, 2007.

. Democratizar a democracia: os caminhos da democracia participativa. São Paulo: Civilização Brasileira, 2002.

Recebido em março de 2010

Aprovado em janeiro de 2011

Arilene Medeiros possui doutorado em Educação pela UFSCar. Professora do Departamento de Educação da UERN. Coordenadora do Programa de Pós-Graduação em Educação e Líder do Grupo de Estudos e Pesquisas em Estado, Educação e Sociedade. Principais publicações: Administração Educacional e Racionalidade: Desafios Pedagógicos (Editora UNIJUI, 2007); Conselho Escolar: Mecanismo de Democratização ou Burocratização (Educação UNISINOS, 2008); Formação do Gestor Escolar no Contexto do Desenvolvimento das Teorias Curriculares (Educação em Questão, 2006). E-mail: arilene.medeirosabol.com.br 